\title{
Educational Equality and National Identity--The Disputes over Yenching Academy and the Internationalization of Chinese Universities \\ LI Chun ${ }^{1}$ \\ ${ }^{1}$ School of Translation Studies, Jinan University, Zhuhai, Guangdong, 519070, P.R. China
}

\begin{abstract}
The initiation of Yenching Academy, as an institution to promote internationalization of higher education, was controversial for its inequality in treating Chinese students and international students. This inequality resulted from China's past traumatic historic narrative and its demand for a higher international profile, involved by nationalism. The right way to promote internationalization is to replace this nationalism with universalism.
\end{abstract}

Keywords: Yenching Academy, educational equality, internationalization, nationalism

\section{INTRODUCTION}

The disputes over Yenching Academy (YA) on mass media in the middle of 2014 has been ranked as one of the most influential cultural events of that year in China.

Aiming to attract 100 top talented graduates from world top universities and cultivate future global leaders, YA, as an embryonic institution of Peking University, is designed to offer a one-year MA program called "Chinese Studies", which includes six divisions: literature and culture, history and archaeology, philosophy and religion, public policy and international relations, economics and management, law and society.

Among all the admitted students, i.e. Yenching Scholars, the number of international students would prevail over that of Chinese students by $65 \%$ versus $35 \%$. As courses offered by the program will be taught totally in English, those international students are not necessarily required to speak any Chinese at all, and the teaching faculty will be consisted in mainly by international teachers, whose salaries will be commensurate with "international standards." This highly-internationalized program also promisesto provide each Yenching Scholar with a full scholarship, covering their tuitions and living stipends.

Nevertheless, this ambitious program turned out to be controversial, from which we can acquire a panoramic view of the problems related to China's education system, especially the internationalization campaign highly-promoted in Chinese universities.

\section{Inequality: from Personal to International}

The establishment of YA was officially declared on May 5th, 2014. In no time, this initiative encountered strong oppositions first on campus, later among alumni and intellectuals on mass media.According to a survey taken among Peking University students, faculty and alumni, 1433 of all 3028 people surveyed were opposed to the program, with 1341 neutral and only 308 in favor. It also showed that the objection to this program was mainly due to its location. [1]

As a residential college, YA is designed to be located in Jingyuan Garden, a central area of Peking University campus featured with a big lawn flanked with traditional Chinese courtyard houses. It had long been housing Department of Chinese Language and Literature, Department of History, and Department of Philosophy. Not long before the release of YA, Peking University had moved those three departments from Jingyuan Garden to the newly-built Lee ShauKee Humanities Buildings.

Because of the high prestige enjoyed by these three departments, Jingyuan Garden had amounted to be a place embedded with high cultural and spiritual values.While Peking University declared that it would 
renovate the Garden to provide accommodation for Yenching Scholars, the conceptual renderings of the Academy's buildings and facilities, which appeared to be extremely luxurious like "a private club", were revealed on the internet. This immediately ignited uproar on campus.

Firstly, students and faculty, especially those from the three departments afore mentioned felt discriminated for being forced to sacrifice a long-resided beautiful home full of memories and make room for those so called elite Yenching scholars. Secondly, the renovated Jingyuan Garden, as the renderings showed, would change a lot in its structure and appearance. This was reckoned as a strong disrespect of the feelings of the students, faculty and alumni. Additionally, the luxuriousness of the facilities and the rumor that Jingyuan Garden would since be forbidden to other students and teachers engendered a strong sense of being expelled and discriminated. Thirdly, more than 1,000 first year graduate students enrolled in 2013 were assigned to be accommodated on Yuanmingyuan Campus, an attached campus about 3 kilometers away from the headquarterscampus, because the university authorities declared that there was not enough space on the headquarters campus. Compared to the favorable living conditions offered to Yenching scholars, the relatively unsatisfactory living conditions of these students were naturally reckoned as an evidence of being discriminated again.

Criticisms also targeted at the one-year program, which was thought to debase current Peking University degrees because Yenching Scholars could get their master's degree just after one year's study while other graduate students should spend two years or three years.

Generally speaking, most of the criticisms were related to the problem of educational equality. The inequality was not just personal, but also international. A Douban netizen named "Polar Bear", probably a Peking University student, expressed his anger: "If all of the 100 students are Chinese, will Peking University build an 'ivory tower in ivory tower' for them, establish this independent, exclusive residential college, and offer them
$\$ 2,000$ per month, teach them 'Chinese Studies' in English? Therefore, the 35 Chinese students only play ornamental roles. Otherwise, is there any difference between this 'ivory tower in ivory tower' and 'country in country'-western settlements in Chinese territory in the past?’'[2]

This argument was very typical among dissenters. Here, personal inequality on campus has been analogized with the inequality China suffered in the past, and complicated by the reference of nationalism. What is interesting is that the justifications of YA and "Chinese Studies" by Peking University authorities are also engaged in national discourses.

\section{Trauma or Appeal: Two Nationalist Discourses in Defending "Chinese Studies"}

Why Peking University was so hasty to attract international students in "Chinese Studies" in such a generous way, at the risk of offending its students and faculty? According to Professor Liu Wei, vice-president of Peking University, and also newly-appointed dean of YA:"China has left to the whole world an image of a country enjoying quick development and prosperity, however, is not sufficiently understood and respected... the Chinese people has turned to be greedy and speculative in other peoples' eyes. They have seen a lot of our negative sides and even asked: what has this nation brought to our world? ... We hope the world would acquire an objective, comprehensive and deep understanding of what we really are...we are thinking about to promote deeper understandings of China through this platform."[3]

These comments made by Professor Liu at a private meeting with Yenching University alumni first revealed that the fundamental motivation to start the Academy originated from the agony that China has not won the respect commensurate with its economic status. He attributed China's negative profile to western people's ignorance and misunderstanding of China. This argument could be reckoned as a legacy of China's revolutionary discourses, or an updated version of China's modernity. 
China's way to modernization started from its being engaged into the world system by the western powers through wars, invasions and unequal treaties in late Qing Dynasty. This resulted in a traumatic narrative of China's modernization. Intellectuals and social activists from one generation to another since then have been unanimously confirming the belief that the nation should become strong, thus to build an independent country, free from the bullying and oppression of western countries.This sense of trauma has also created a widespread "common sense" among the Chinese people that we are living in a country mistreated and misunderstood by the western countries and to strive for a wealthy and powerful country is the only right way we should take.

A commentary by People's Daily best exemplifies this traumatic version of China's modernity:"It is said that our sufferings of being bullied were ended by founding a new China, and our sufferings of being hungry were ended by carrying out the reform and opening policy, while now, we need to end our sufferings of 'being maligned'. The subordination of current China to Western discourses is a result of our inferior status in modern history and of the setbacks encountered in the course of our development. In the process to realize our Chinese Dream, and to become a big power in the world, how could it be possible to talk about academic independence and influence, cultural infiltration and appeal without an agreeable, emissive and persuasive discourse system? Therefore, the return of Chinese Studies to China proper will pave the way for our domination of Chinese Studies and will usher Chinese discourses into the hall of the world family. " [4]

Here, "being bullied", "being hungry" and "being maligned" are typical traumatic narratives of modern Chinese history, and have been serving as the dynamic of China's revolution and modernization. Now, it was appropriated to justify the Chinese Studies program.

However, on another occasion, Professor Liu gave a different explanation: "As China is becoming stronger and stronger economically, more and more influential culturally, issues related to China have become the hot topics in international academia," said Liu to a reporter of
Guangming Daily: "Yenching Academy thus initiated 'Chinese Studies' to foster future global leaders with a vision of 'understanding China, contributing to the world'."[5] Here, the traumas of China in the past years are not mentioned. As China is a big and powerful country, the western world requires to know it more. YA's mission is to satiate that requirement and present the intrinsic appeal of Chinese culture. Some people believe it is a necessary step for a rising big country to claim its status:"Aculture full of confidence is more likely to be promoted abroad. Before the initiation of 'Chinese Studies' program, we had gone abroad to establish Confucius Institutes in many countries. So to speak, it is an action to 'set up our own stages and put on our own shows'. Now we are more confident in that we have sufficient resources to invite guests home to study China. This is undoubtedly a symbol of our national power and cultural confidence." [6]

Here, it is not an endeavor to eliminate the misunderstandings held by the more or less hostile western world, but an action to show the glory and appeal of Chinese culture, thus to build a positive image of a big country.

Both of these two justifications are involved in some nationalist discourses. One originated from the traumatic narrative of modern Chinese history, and the other from the recent upsoar of China's economic power. Both are not satisfied with the current status of China in the world and are striving to claim a new one.

\section{National or International?}

In 1998, former Chinese president Jiang Zeming launched the campaign to "construct world-class universities" at the 100th anniversary of Peking University. From then on, internationalization has been one of the basic goals of Chinese universities. YA was one of Peking University's efforts to reach a higher level of internationalization. As Professor Liu Wei said:“Chinese culturehas an integrated, unbroken and long-lasting history of more than 5,000 years, which suggests that it is definitely embedded with some valuable elements. It is the contribution of Chinese 
Studies to the whole world and the reflection of our cultural confidence to refine these elements with modern academic paradigms, and to promote them in international and academic languages, thus to help Chinese culture to play an leading role in this era characterized by economic prosperity as well as turmoil.."[7]

These comments best reveal the logic as well as the problems of Chinese universities' internationalization campaign. The motivation to be internationalized is to promote Chinese culture, and to claim a highly influential status of China in the world. From this we can see there is a latent nationalist intention wrapped in this internationalization movement. However, here appear some problems, of which the most important one is the relationship between national and international.

First, what is that "internationalization" we want? Does it mean to follow western models and to attract more international students and faculties? Professor Wang Bo, vice-dean of YA, envied Harvard University, at a promotional meeting of YA, for its plural cultural background, which was best proved by the 50 languages spoken on campus.Then, if internationalization means to model western universities like Harvard and to follow western rules, how could we talk about promoting Chinese culture and cultural confidence with our own subjectivity?

This contradiction has made YA initiators try to convince their compatriots that those generous conditions were necessary, effective and rewarding to attract international students, because it would finally help to promote the international status of China, while on the other hand, they had to hide this latent nationalist intention and to show a kind of universalist hospitability on international stages. For example, Professor Zhang Xudong, another initiator explained the necessity to start YA: "It is a great challenge for us to tell our experiences, traditions, and stories in front of those westerners who claim to be the spokesman of the truth." [8] While this hostility was mediated by a pluralism in YA advertisements, for example, one posted on Stanford website reads: "The
Yenching Academy provides an extraordinary education experience that draws from western and eastern perspectives; cultivates leaders who will advocate for global progress and cultural understanding." [9] This contradiction indicates the challenge China, as a rising country, is faced with in its way to be accepted in the world family. As it is becoming a great power, it demands a higher profile and subjectivity globally, but it seems more effective to make some compromises to western values and standards, while at the same time, these compromises are contradict to its claim for fuller subjectivity and open to controversy domestically.

In this case, the internationalization movement of Chinese universities must change its strategy, from political and national oriented to universal, academic oriented, thus to remove impediments home and abroad.

\section{Conclusion}

The disputes over YA have revealed the embarrassing situations Chinese Universities are faced with in their road to internationalization. The most important characteristic of this internationalization is that it is motivated by a national willpower, which has made it controversial and hindered. It is no doubt that internationalization should be taken as a goal, but it should be relieved of some national and political commitments. As far as universities are concerned, their goal must be set to serve the whole world, to develop civilization, to cultivate people, etc. They should also concentrate on improving the quality of students and faculty, teaching and researching. This universalism and return to academics proper might lead to internationalization and raise their standing in rankings finally, but here is a precondition:"Giventime, the goals are achievable, but time must be given.”[10] 


\section{References}

[1] "Yanjing xuetang dashiji (A Chronicle of Yenching Academy)," Beijing qingnian bao (Beijing Youth Daily), p.D03, 2014-7-4.

[2] http://www.douban.com/note/356875040/

[3] http://www.yenching.org.cn/pages/viewpage.action?p ageId $=3965543$

[4] Huaiyu, Chen, "Zhongguoxue jin ketang yiweizhe shenme? (What does Chinese Studies into University Classes Suggest?)," Renmin ribao haiwai ban (People's Daily Overseas Edition) ,p.7, 2014-5-7.

[5] "Beida qidong yanjing xuetang, jihua quanqiu xuancai yanjiu zhongguoxue (Peking University Initiated Yenching Academy, Ready to Recruit
Students Worldwide in Chinese Studies)," Guangming ribao (Guangming Daily), p.6, 2014-5-6.

[6] http://review.qianlong.com/20060/2014/05/06/8145@ 9593886.htm

[7] Wei, Liu, "Women weihe yao dazao zhongguoxue xueke (Why we initiated Chinese Studies )," Guangming ribao (Guangming Daily), p.13, 2014-6-17

[8] http://weibo.com/p/1001603729325902929990

[9] http://icenter.stanford.edu/orc/yenching_academy.htm 1

[10] http://en.cncurrent.com/as-chinese-universities-targe t-global-elite-spending-fails-to-bringreturns/ 